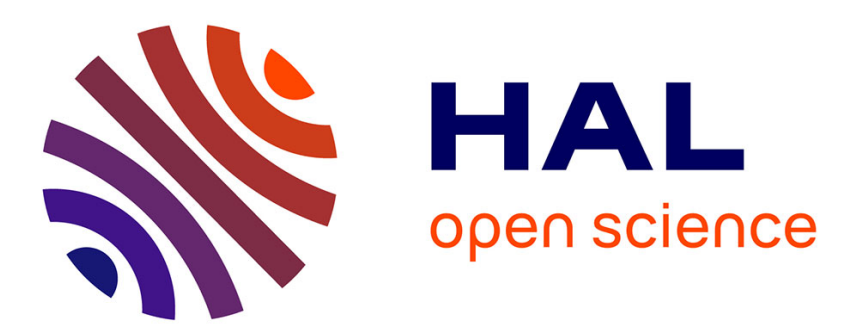

\title{
"Sick but active, tired but healthy". Narratives of body and self living with HIV
}

\author{
Laura Schuft, Sylvain Ferez, Alessandro Bergamaschi, Fabienne
}

d'Arripe-Longueville

\section{- To cite this version: \\ Laura Schuft, Sylvain Ferez, Alessandro Bergamaschi, Fabienne d'Arripe-Longueville. "Sick but active, tired but healthy". Narratives of body and self living with HIV. Qualitative Research in Sport, Exercise and Health, 2021, pp.1 - 16. 10.1080/2159676X.2021.1969997 . halshs-03331401}

\section{HAL Id: halshs-03331401 https://shs.hal.science/halshs-03331401}

Submitted on 5 Sep 2021

HAL is a multi-disciplinary open access archive for the deposit and dissemination of scientific research documents, whether they are published or not. The documents may come from teaching and research institutions in France or abroad, or from public or private research centers.
L'archive ouverte pluridisciplinaire $\mathbf{H A L}$, est destinée au dépôt et à la diffusion de documents scientifiques de niveau recherche, publiés ou non, émanant des établissements d'enseignement et de recherche français ou étrangers, des laboratoires publics ou privés. 
Laura Schuft, Sylvain Ferez, Alessandro Bergamaschi, Fabienne d'Arripe-Longueville (2021).

\title{
"Sick but active, tired but healthy". Narratives of body and self living with HIV
}

The Version of Record of this manuscript has been published and is available in

Qualitative Research in Sport, Exercise and Health, https://doi.org/10.1080/2159676X.2021.1969997

\begin{abstract}
Although studies have suggested that physical activity may diminish HIV-related fatigue, little is known about the physical experience or meanings attributed to either. We considered chronic fatigue and physical activity in terms of how they were experienced, interpreted and interrelated within narratives about living with HIV. Thematic analysis of 35 semi-structured interviews with people living with HIV in France led to the creation of four ideal-type narratives. The ideal types illustrated relations between diverse physical and social experiences of fatigue and physical activity. These dimensions of the HIV experience were part of larger identity narratives about the body and self, revealing tensions between the latter as healthy or ill, tired or active, vulnerable or robust, needing or heeding expected health behaviours. Illness narratives - and the meanings attributed to body and self - emerged as faceted by both physical experiences of the body and social experiences, and as situated within larger socio-political contexts and biopedagogies.
\end{abstract}

Key words: fatigue, physical activity, exercise, chronic illness, illness experience 


\section{Introduction}

Much literature has documented illness experience and identity adjustments among people living with the Human Immunodeficiency Virus (HIV) (Baumgartner and David 2009; Ciambrone 2001; Thorpe 2009; Wouters and Wet 2016). Whether constituting a major "biographical disruption" (Bury 2001) or a "life-event" (Goffman 1963) among social and economic hardships (Ciambrone 2001; McGrath et al. 2014; Wouters and Wet 2016), HIV diagnosis entails a certain amount of ongoing adaptations or identity work. These adaptations are in interaction with HIV stigma (Geary et al. 2014; Marsicano et al. 2014; Smith, Rossetto, and Peterson 2008) and the illness itself, including medical monitoring or the management of symptoms or treatment side effects (Alexias, Savvakis, and Stratopoulou 2016; Schuft et al. 2018).

The experience of illness symptoms or health recommendations are also integral to the social construction of illness (Conrad and Barker 2010) and the self living with chronic illness (Baumgartner and David 2009; Charmaz 2002; Clarke and James 2003). Chronic fatigue and physical activity - viewed respectively as an illness symptom (Schuft et al. 2018) and recommended health behaviour (Duval et al. 2016; Ferez and Luauté 2008) among people living with HIV (PLWH) in France - have rarely been studied qualitatively or in relation to each other. This study seeks to address the physical experiences and social significations of HIV-related fatigue and physical activity, their interrelations, and how they were woven into narratives of "a coherent self" (Bury 2001).

\section{Conceptual background}

HIV has emerged as a "chronic" illness since the success of combination antiretroviral treatment (ART) in the late 1990s (McGrath et al. 2014). ART has allowed to keep viral loads low or even 
"undetectable", at the cost of regular treatments - or "pill burden", although the side effects of this burden have lessened with increasingly "simpler and better tolerated" ART regimens (Costa et al. 2018). Chronic illness has long been considered transformative of the self (Baumgartner and David 2009; Charmaz 2002; Clarke and James 2003), resulting in transformed identity narratives - or “illness narratives" (Bury 2001; Frank 1993). Illness narratives can be considered "a significant means for studying the social construction of illness as a rhetorically bounded, discursively formulated phenomenon" (Frank 1993). As illness narratives account for "the altered relations of body, self and society brought about by illness" (Bury 2001: 276), they are viewed here as drawing from - and giving meaning to - the physical, psychological and social experiences of health and illness.

Narratives - or the performative act of "doing storytelling" (Smith \& Sparkes, 2008) - can be articulated with actions and agency, or "doing" chronic illness (Thorpe 2009). The latter concept considers that people have agency to "choose" to a certain extent how they live with or manage chronic illness. Recent research has suggested that such "choices" as well as the physical experience of HIV are facetted by social contexts of interaction, and an interplay between the sentiment of HIV (in)visibility (Persson 2005; Thomas et al. 2014; Alexias et al. 2016) and the acceptability of disclosing HIV or physical symptoms (Mackworth-Young, Bond, and Wringe 2020; Schuft et al. 2018). These findings suggest that illness narratives are influenced by both physical experiences - regarding the body, treatments or symptoms - and social experiences along illness trajectories. The embodiment of physical and social experiences is thus central to our consideration of how people "do" and narrate illness experiences, how they represent the bodyself, or how they "craft" new understandings of what it means to be an individual living with HIV. 
Fatigue is a major physical symptom associated with HIV (Zhu, Zhao, and Hu 2019) and has been widely studied in terms of correlations with psychological and physiological variables. Although the principal correlation appears to be depression, results have suggested that social factors such as socioeconomic conditions or social support are major predictors, while clinical variables such as date of diagnosis, treatment histories or viral load have yielded inconclusive or contradictory results (Barroso and Voss 2013; Bergamaschi et al. 2019; Harmon et al. 2008; Hughes et al. 2020; Jong et al. 2010). Recent work has complemented these studies with qualitative approaches to HIV-related fatigue and its social significations (Schuft et al. 2018), following work on fatigue related to chronic fatigue syndrome (Clarke and James 2003; Olson, Zimka, and Stein 2015) and other chronic illnesses (Olsson, Stafström, and Söderberg 2013). In this study we focus on how the experience of fatigue is associated with physical activity in narratives about living with HIV. We refer to HIV-related fatigue as "chronic exhaustion" associated with HIV (Jenkin, Koch, and Kralik 2006), as opposed to exercise-induced "acute physical fatigue" (Kluger, Krupp, and Enoka 2013).

Studies suggest that chronic fatigue among PLWH may be reduced by regular physical activity (Bergamaschi et al. 2019; Webel et al. 2016). As among the general population, physical activity programmes for PLWH have been associated with other health benefits such as lower anxiety and depression, improved physical capacities or higher quality of life (Quiles, Ciccolo, and Garber 2017; Voigt, Cho, and Schnall 2018). Yet despite increasing knowledge and beliefs about the benefits of physical activity, few studies have considered the experiences and views of physical activity by PLWH (Ferez et al. 2014; Gray et al. 2019), or their relations with the experience of physical symptoms or with exercise recommendations from health professionals. 
Public health messages have increasingly encouraged physical activity as well as other health-enhancing behaviours for the general public, all while particularly targeting people living with chronic illness (Newman et al. 2016) including HIV (Duval et al. 2016; Ferez and Luauté 2008). Some doctors and clinical publications have recommended promoting health-enhancing behaviours like physical activity as symptom-management strategies, including for HIV-related fatigue (Perazzo et al. 2017). Targeted messages promoting rationalized health behaviours can be considered what Foucault termed "biopedagogies": medical discourses which lead to forms of "governing" or disciplining certain bodies (Rail 2012; Wright and Harwood 2012). Recently emerging as a useful concept to analyse public health policy regarding obesity in particular, "biopedagogies revolve around the moral regulation of bios or life (i.e., how to eat, how to move, how to live)" (Rail 2012, 229). As several authors have noted (Newman et al. 2016; Wright and Harwood 2012), these biopedagogies "draw on a neoliberal notion of individualism that constructs individuals as at once capable of and responsible for changing their lifestyles through a variety of disciplinary techniques" (Rail 2012, 229). In this light, experiences and interpretations of fatigue and physical activity may reflect ways in which PLWH negotiate self in the face of illness symptoms and management, or how they embody, resist or give meaning to biopedagogies - in terms of moral views about self-disciplinary measures surrounding health behaviours and physical activity.

\section{Methods}

\section{Methodological underpinnings}

We considered illness narratives to be rich data sources for social analysis when socially contextualized and considered systematically across participants' stories (Atkinson 2009). Despite 
diverse or unique interpretations and meanings attributed to individual illness experiences during the performative act of narrating, we can agree with Atkinson (2009) - within the "contested terrain of narrative methods" (Thomas 2010) - that the collective dimensions of illness experiences and meanings within sociocultural contexts can enhance understanding of the "social construction of illness" (Conrad and Barker 2010). As our research focused on discourses and themes across narratives, and less on storylines in terms of their individual chronology, uniqueness or performative delivery (Smith and Sparkes 2008), we combined the narrative approach to data collection with an analysis based on the principles of reflexive thematic analysis (Braun and Clarke 2021). This approach enabled us to first generate a rich dataset of in-depth individual experiences and interpretations through narrative, to situate these particularities within collective social dimensions across the dataset through thematic analysis, and to later re-think themes and meanings in relation to narrative "types". The methodological flexibility allowed reconciling between focus on the particular and the general, and between approaches stemming from inductive and deductive epistemologies.

Within a relativist ontological approach to data collection and rigor (Sparkes and Smith 2009), criteria for reliability was not viewed as necessarily improving the accuracy or trustworthiness of analyses, owing that "theory-free knowledge is unachievable and that realities are subjective" (Smith and McGannon 2018, 12). We nonetheless took steps to meet basic standards of methodological rigor to increase the representativity of data (data saturation) or the consistency of interpretation (triangulation), as discussed below, while recognizing from a relativist approach "that the goal of doing so is not to provide researchers with a more valid singular truth" (Tracy 2010, 844). In this light, we considered our analyses from an interpretivist approach, as co-constructed between participant and researcher understandings and subjectivities. 


\section{Participant recruitment}

Participants were recruited through three major French hospital services specializing in HIV care as well as through three non-medical associations offering services such as leisure activities, social support and information for PLWH. The hospitals and associations were located in three regions in the centre, the southeast and the south of France. The aim was to obtain the perspectives of PLWH with diverse social and medical profiles in a nationwide sample, without imposing specific inclusion or exclusion criteria.

In each hospital, we contacted the department of HIV and infectious disease and organized a meeting to present the study to the practitioners. Each head of service then accepted to attribute a Clinical Research Assistant (ARC) from their service to recruit participants. Using a flyer and consent form, the ARC presented the study and its ethical guarantees, and proposed participation to every consecutive patient who came for their regular consultations over a set period of a month. In the associations, we contacted staff and organized discussion sessions with the associations' beneficiaries to present the study and its ethical guarantees and to discuss the themes of HIV and a) physical activity and b) fatigue. At the end of each discussion session, which allowed us to become familiar with experiences and views regarding these topics, PLWH were invited to participate in the study.

\section{Interviews}

Volunteers recruited through these methods were later contacted by a researcher. Prior to their interview, participants signed a consent form which informed about: the project objectives; their liberty to decline or withdraw from the study; and the confidential and anonymous nature of 
data storage and analysis. On these ethical bases the study had previously obtained ethical approval with the French National Commission for Data Protection and Liberties (CNIL). Semi-structured interviews were conducted in spaces provided by the hospital services and associations, as well as in participants' personal homes, depending on the preference and availability of the participants. Interviews lasted an average of two hours and were conducted in French. For the purposes of this publication, the selected excerpts were translated by a bilingual native English-speaker then verified by cross-translation by a native French-speaker.

Thirty-five interviews were conducted over six months, ending when researchers felt they had reached "data saturation", indicating a stage when researchers felt they had heard a "repetition of responses" or "the same comments again and again" (Saunders et al. 2018). In line with relevant qualitative work outside of grounded theory, we considered data saturation - as opposed to "theoretical" or "thematic saturation" - as a helpful indicator for ending the collection of narratives at the level of data collection, in a manner unrelated to later phases of analysis or theory (Saunders et al. 2018). Although "saturation" is a contested concept for reflexive thematic analysis (Braun and Clarke 2021), we viewed data saturation as coherent with an interpretivist approach. Rather than translating an assumption that "nothing new" could be garnered from further interviews, data saturation represents a subjective researcher perception of redundance, marking a turning point in phases of research.

The first section of the interview topic guide broached (dis)continuities in daily life following HIV diagnosis, with an aim to consider the overall illness experience and any mention of physical activity or fatigue. The second section concerned relations to and representations of physical activity, while the third focused specifically on the experience and interpretations of fatigue, including perceived causes and consequences. The interview ended with the completion 
of sociodemographic information including age, occupation, country of birth and year of diagnosis. The interviews were transcribed verbatim and rendered anonymous. A table was created to keep track of pseudonyms, interview date and place, sociodemographic data and brief summaries of physical activity and fatigue levels as described by the participants.

\section{Participant characteristics}

The participants were diagnosed between 1983 and 2010, the median year of diagnosis being 1994. The distribution of gender and sexual orientation among participants represented more women as compared with distributions in the national context (46\% versus $33 \%$ ), but also more men who have sex with women (MSW) (20\% versus 28\%) and less men who have sex with men (MSM) (34\% versus 39\%) (Dray-Spira et al., 2013). In terms of professional activity, a third of the participants qualified for handicap or unemployment benefits. This was comparable to available national data for handicap benefits, received by $21 \%$ of women and $14 \%$ of men living with HIV (Lert et al. 2013). Lastly, France as a country of birth was over-represented in the interviewed population, as only 4 participants were born outside of France, while people born in Sub-Saharan Africa alone recently represented 38,7\% of new diagnoses in France (ANRS 2018). All of the participants were following medical care and treatments. Although the recruitment process may have favoured participants with medical complications, medical history was not considered in a systematic way due to the great diversity in medical profiles and temporalities, as well as previous contradicting or inconclusive quantitative results linking fatigue to treatments or biological markers, as stated above. 


\section{Analysis}

The first stage of analysis involved deductive thematic analysis in which all discourse pertaining simultaneously to fatigue and physical activity was coded within an umbrella category. This category was then subject to inductive thematic analysis, in which recurring concepts generated initial codes and then themes of analysis (Braun and Clarke 2019). A triangulation of analyses by three researchers (Nowell et al. 2017) involved sharing one researcher's initial coding to critically discuss the themes of analysis and later reach a form of agreement on the overall interpretation of data via the themes of analysis and coding. In this light, the multiple researchers acted as "critical friends" (Smith and McGannon 2018, 24), seeking less to verify "intercoder agreement" or "trustworthiness" than to provide a process in which interpretations could be confronted, developed and then mutually agreed upon.

During a later phase of thematic analysis as defined by Braun and Clarke (2019), where "researchers review the coded data extracts for each theme to consider whether they appear to form a coherent pattern" (Nowell et al. 2017, 9), the themes were re-organised to test the trend that themes varied by levels of fatigue and physical activity. This re-organization gave way to an original analytical framework in the form of a graph (Figure 1) in which coded meanings were considered in relation to individuals' physical experience, in terms of physical activity (whether physically active or not) and fatigue (whether experiencing chronic fatigue or not). This created four "ideal types" in the sense of Max Weber: exaggerated archetypal forms of classification that facilitate the categorization and analysis of otherwise elusive concepts or phenomena (Swedberg 2017). The ideal types were understood through an interpretivist paradigm, as an imperfect means of interpreting the diverse lived and recounted experiences. Because levels of physical activity or fatigue are also subjective and variable over time, the ideal type narratives were theorized as 
situated along intersecting continuums of reported levels of fatigue and physical activity (Figure 1). A continuum model of ideal types, as has previously been proposed in the domain of health and physical activity (Christiansen, Vinther, and Liokaftos 2017), allowed us to situate, theoretically, significations attributed to fatigue and physical activity in relation to their physical experience. It also allowed us to situate related themes, such as the importance accorded to "healthy living" or "preserving the vulnerable body", in relation to these social meanings and physical experiences.

\section{[Figure 1 near here]}

\section{[Table 1 near here]}

\section{Findings}

The ideal type narratives are each described in terms of the related themes of analysis, samples of coded discourse and how people conveyed the body and self living with HIV. Interpretation of these findings will be broadened in the discussion section.

\section{"No sport due to fatigue"}

The most predominant ideal-type profile involved those who reported chronic fatigue and physical inactivity. They viewed physical activity as ill-adapted to their state of health, or too fatiguing for the "sick" body. The body-self emerged as vulnerable and strongly associated with HIV. 


\section{Fatigue as a barrier to physical activity.}

The topic of physical activity was met with reactions evoking fatigue: "I'm already too fatigued" or "I don't have the energy" (Marie, 48, unemployed with handicap benefits, diagnosed in 1986). In relation to the physical demands of her children, one woman recounted:

“Playing ball, whatever, it's ok 5 minutes, but after, I just can’t. Because I feel, after, tired and prefer to sit down on a bench" (Marion, 34, homemaker, diagnosed in 2008).

Physical fatigue or exhaustion were regularly cited as obstacles to physical activity. Yet the discourse surrounding such statements revealed other processes relating to illness and symptom experiences. For Janine, lack of energy was part of her description of living with HIV:

“Even just going to the pool, it's... (heavy sigh). You say you're tired before even leaving for the pool. It requires an effort which... You know you won't be able to make that effort" (Janine, 44, unemployed, diagnosed in 1986).

When asked about physical activity, she replied that she was inactive, mentioning also cost as a barrier. However, Janine later termed cost an "excuse":

"You look for the excuse, saying: 'Well, it's expensive'. [...] So, it makes you feel less guilt. Because the doctors, the association, they push you to do things, to not stay isolated, and get out... but um... we know we're tired (laugh), that we won't be able to do it [...] It's easier to say, 'I'm not going because it's expensive' [...] . Psychologically, it brings you back to the illness to say, 'If I didn't have this illness [...] I would do so many things, if I wasn't all the time exhausted!'”.

This excerpt demonstrates the tensions between (un)desired narratives of the self, involving recognizing or denying symptoms (fatigue) or the capacity to live up to expected health behaviours (physical activity) pushed by doctors and HIV associations. Although fatigue was described as an 
obstacle to physical activity, alternate "excuses" enabled her to portray herself as less handicapped by illness.

Physical activity as fatiguing or risky.

Physical activity also emerged as too tiring or risky for one's state of health and energy: "I don't do the whole session (of yoga at the HIV association), because it's too much for me! And I'm not ashamed to say it there" (Marie, 48, unemployed with handicap benefits, diagnosed in 1986).

"We fatigue too fast to follow others. It's not possible! Even yoga [...] Too bad there aren't low-intensity fitness courses, just for us" (Carla, 56, unemployed with handicap benefits, diagnosed in 1983).

Many of these participants used the collective "we/us", anchoring illness-related difficulties in collective HIV identity or experience. This was compatible with an appeal for HIV-specific solutions such as adapted physical activity.

Physical activity was deemed "too tiring", the body too vulnerable. Three participants explicitly viewed HIV as "a sword of Damocles hanging over my head" (Marie, André, Christian), meaning a permanent threat to their well-being if not their lives. For many, this threat was linked to the need to "preserve" the body from over-exertion:

“I don’t smoke. Alcohol: I drink sentimentally, not abusively. And I preserve myself a lot. So if I really need some time for rest, I rest. [...] Outside of work, I come home, I stay at home, a small walk with the family and that's it" (Bernard, 50, skilled worker, diagnosed in 1997). 
Avoiding smoking and alcohol but also many forms of physical activity (in terms of duration, intensity or rest time) were construed as measures to protect or preserve the body. This is in direct opposition with other ideal type narratives where physical activity emerged as a "healthy living" strategy to prevent or manage illness and its symptoms. The "No sport due to fatigue" narratives told a story in which the HIV-infected body and self were vulnerable, and could not or should not over-exert or engage in physical activity.

\section{"Sporty to manage fatigue"}

Among PLWH who felt regularly fatigued but engaged in some form of physical activity, physical activity was still strongly related to fatigue. It was presented as a part of "healthy living", and essential for managing illness and symptoms such as fatigue. "Healthy living" was also at times construed as particularly important for people who are "sick", whether for managing or actively combating illness or its symptoms.

\section{Physical activity as a part of "healthy living" and illness management.}

In these narratives, participants presented physical activity in light of its benefits in terms of illness or symptom management. Paulette (42, teacher, diagnosed in 1996) explained that physical activity "helps me" to manage fatigue, which she associated with both HIV and her work. Similarly, Corentin specifically became a yoga instructor after his diagnosis, viewing yoga as a means of managing life with HIV. Physical activity represented "a boost of energy" and a means of countering illness symptoms, like reduced physical "endurance" for accomplishing everyday activities: "playing sports makes you less tired" (Corentin, 43, part-time yoga teacher with handicap benefits, diagnosed in 1998). 
Physical activity was also viewed as part of "healthy living", presented as a set of behaviours that could both prevent and improve illness:

"Sport or a healthy lifestyle will prevent disease from happening if you are not sick, and if the disease is there, it will improve things a lot" (Corentin).

Other participants described how this narrative reflected discourse relayed by HIV social and medical networks, where workers warned about the dangers of "unhealthy" lifestyle choices:

"We're sure of [the importance of "healthy living"], too, because they were telling us about other people who had lives a little out of control, or things like that who didn't respond as well to treatment as we did" (Pauline, 40, sales assistant, diagnosed in 1999).

In this way, representations circulating in HIV social and medical networks linked physical activity and "healthy living" to health outcomes, encouraging/discouraging particular social behaviours deemed "(un)healthy" - such as diet, levels of rest or intensity of exercise, but also "partying", drinking or smoking.

Physical activity as a means of combating illness.

Beyond managing illness and symptoms, physical activity was also at times represented as a means of actively combating fatigue:

"I refuse to let fatigue take over, because otherwise I go to bed and it's a disaster! [...] I really force myself to... I have to get busy! [...] I have to not think about it [fatigue]. Because if I listen to myself... [...] then, I don't do anything!" (Joelle, 42, unemployed with handicap benefits, diagnosed in 1996).

Others spoke similarly of forcing oneself "to move": 
"Whenever I was tired or coming out of major illnesses [...] even if it didn't last long, I had to go (to physiotherapy), I had to move!" (Isabelle, 51, unemployed with handicap benefits, diagnosed in 1990).

In these narratives, individuals emerged as taking control of their "fight" against illness and its symptoms by adopting behaviours promoted by health messages.

\section{"Healthy because sporty"}

Physically active participants who were not fatigued also construed physical activity as an essential part of healthy living and illness symptom management. Yet here physical activity was represented as their source of good health, the recipe for keeping illness and fatigue at bay. To reach this aim, the type and intensity of physical activity were specified as necessarily "moderate" in intensity and duration.

Illness and fatigue kept at bay "thanks to" physical activity and healthy living.

These participants tended to distinguish between "good fatigue" and "negative" or illnessrelated fatigue. "Good fatigue" was linked to regular, "normal" or chosen activities such as work or physical activity. This fatigue was described as one "where we recover quickly", as opposed to "fatigue due to HIV" where "there's nothing we can do about it" (Michel, 52, administrator, diagnosed in 1991). In the various descriptions opposing "good" versus illness fatigues, "energy fatigue" was compared with "a real physical fatigue", the two types being "not the same fatigue".

For some, physical activity represented an antidote to illness fatigue: sport "chases away the fatigue [...] You feel good and it takes away fatigue" (Philippe, 35, massage therapist, 
diagnosed in 2008). More dramatically, for George, physical activity "saved" and "changed" his life, allowing him to improve his "quality of life" and "fight" off illness:

"It gives me energy, it motivates me... [...] It's also social. [...] It saved my life! It's what... psychologically, physically, I think it's the most important things that I've done, to stay very active... For example, bodybuilding, for me, it's like a rebooting, rebooting a computer. [...] I can be psychologically fatigued after work or whatever, I go to my sport, and... when I get home, everything's fine!" (George, 50, consultant, diagnosed in 1995).

Similarly, Giorgio depicted physical activity as an instrument of illness management, as part of his "cure for AIDS" (used here in lieu of HIV):

"I discovered the true medicine for AIDS, $[\ldots]$ healthy living! [...] Life discipline, sport, going out, being active, never lazy, making oneself be active! [...] That's my prescription. You mustn't stay at home, in front of the television day and night" (Giorgio, 54, capital manager, diagnosed in 2002).

In these last excerpts, being energetic or active was not only associated with "good fatigue" and health, but also with a moral value of "effort" and a positive frame of mind. Conversely, lacking energy or activity was associated with illness but also laziness and a negative frame of mind.

\section{Moderate physical activity as the appropriate form of health management.}

Not just any physical activity, or any amount of it, was touted as beneficial. Many participants underlined an importance of carefully dosing the amount of physical activity in order to harvest energy rather than fatigue: 
"Sport is a domain which... [...] is useful for relaxing, but $[\ldots]$ I don't see the point of going every day, that's not relaxing, that's fatigue" (Charles, 41, associate director, diagnosed in 1998).

Similarly, Raphael (76, retired teacher, diagnosed in 1987) spoke of avoiding "excessive" amounts of physical activity: doing "a little", "not too much", "not excessively", "not too fast", not too "violent".

Physical activity was also presented as part of normative health behaviours: "part of that healthy lifestyle, part of that regulated life. Not a wild lifestyle" (Giorgio, 54, capital manager, diagnosed in 2002). For many participants, this was considered particularly important for a person "sick with HIV" who "should not exaggerate with sport", and "must not come home exhausted" (Giorgio). In this sense, "moderate physical activity" was explicitly viewed as important means of preserving health for "people who have an illness", due to the precarious health status associated with HIV:

"I had a very balanced life, which is very important in this sickness. [...] A balanced life... moderate physical activity, well, that's ideal. I think that's the ideal for all illnesses!" (Michel, 52, administrator, diagnosed in 1991).

This moderation was associated with "protecting" and "preserving" the body, "because your body is already fighting the illness. [...] We shouldn't get exhausted" (Philippe, 35, massage therapist, diagnosed in 2008).

The surrounding medical and social environments reinforced these narratives about "healthy living" as involving moderate energy and physical activity levels:

"Many around me say 'Maybe you should take it easy, since you're taking a treatment, it's poison for the body and [...] the treatment on its own is exhausting'. [...] Sometimes, the 
recommendations [from the general practitioner] are like 'Ok, maybe you should stop sport'; 'you should stop competition" (Gregory, 38, steward, diagnosed in 2007).

Philippe wondered if his doctor's recommendation "to not get exhausted" was due to his treatments, "seeing as I have an undetectable viral load". His question underlines a contradiction between the physiological reality for many who experience little to no HIV-related symptoms or even viral load, on the one hand, and representations in which HIV is associated with physical vulnerability and a need for protection and moderation, on the other hand.

\section{“No sport, no fatigue, no problem"}

Only four of the interviewed people spoke of little to no fatigue or physical activity. Physical activity was construed as foreign to their personality or lifestyle. In parallel, their body, health and, more largely, life were considered "normal". Physical activity was met with indifference, while inactivity emerged as consistent with identity and lifestyle, and dissociated from HIV.

Physical activity as foreign to one's personality or lifestyle.

These narratives included statements such as: "It isn't one of my usual habits"; "I'm not much of an athlete"; or "I'm lazy" (Fatima, 52, nursing auxiliary, diagnosed in 1992). When asked about physical activity, Fatima further elaborated on this statement, laughing that if she ever did her shopping by foot, "in the evening when I come home, I wouldn't even make dinner! I'd go to bed, because I wouldn't be used to it”. Remy also made light of his physical efforts. When asked if he experienced fatigue, he laughed:

"I'm tired by nature (laugh), because I don't go out! [...] I don't make too much effort to do sport or things like that. [...] No, no, I don't feel tired" (Remy, 55, employee, diagnosed in 1987). 
These participants therefore recount no particular fatigue, but also no particular interest in physical activity.

\section{Health and life as "normal".}

These participants spoke of their health, fatigue and lives as "normal", "like everyone" (Fatima). Fatima sometimes wondered whether punctual fatigue was due to HIV or treatments, but generally did not view fatigue as a result of either:

"I don't know if I'm tired because I work, because I'm taking care of the kids, I'm running here, running there, or if I'm tired because of the medicine or my immunosuppression. I don't know! [...] I wonder, but I don't go beyond wondering... [...] And then I forget, and it passes" (Fatima, 52, nursing auxiliary, diagnosed in 1992).

Overall, for Fatima and her husband, also living with HIV, she referred to their levels of fatigue and energy as "normal":

"Compared to people around us who are the same age as us, they don't seem to be more fit than us. [...] Maybe, if some at our age can do a sprint at $200(\mathrm{~km})$ per hour. We're not athletic so, of course we couldn't follow. But we walk, we work all the time; when there's something to be done, we do it. We don't feel out of breath. Know what I mean?"

Describing themselves as "normal", "unathletic" individuals achieving their regular activities and everyday lives without a problem, they did not integrate illness experience or expected health behaviours into their overall identity narratives. 


\section{Discussion}

One of few qualitative studies on HIV-related fatigue (Perazzo et al. 2017; Schuft et al. 2018), our results also corroborate quantitative work showing correlations with social and economic variables. All of the participants in our study receiving handicap or unemployment benefits spoke of chronic fatigue, as did nearly all of the participating women (see Table 1). These observations are consistent with results having shown that reported levels of HIV-related fatigue are related to class and gender, disproportionately impacting poorer women (Jong et al. 2010), although gender has not recently emerged as a correlating variable (Bergamaschi et al. 2019). The disproportion may be due in part to more ready admission to symptoms among women, while men may be more prone to "hegemonic" masculine gender prescriptions such as showing robustness and dissimulating fatigue or weakness (Courtenay 2000; Schuft et al. 2018). Similarly, women were less physically active in our study, which is consistent with trends regarding gender socialization and sport in France (Mennesson 2011). Such ancillary observations can only suggest a need for greater study of fatigue in terms of social and economic contexts and hardships, which have already been shown to greatly impact the experience of living with HIV (Ciambrone 2001; Wouters and Wet 2016). As gender and socioeconomic conditions also affect social, physical and illness-related behaviours and experiences, they appear to play an indirect role in narratives about the latter.

More specifically our results showed the relations between the physical experiences of living with HIV, the meanings attributed to these, and narratives about the body and self. The ideal-type discourses and significations surrounding experiences of fatigue and physical activity particularly illustrated different "moral narratives", in which individuals "seek to account for and perhaps justify themselves in the altered relations of body, self and society" and (re)establish their moral status (Bury 2001, 276). This entailed underlining or justifying (non)conformity to 
normative health behaviours like physical activity. Due to transversally described pressure to engage in "healthy living" due to illness or HIV, those who described being inactive due to fatigue often evoked guilt for not following this moral order emanating from HIV and medical communities. Advice on physical activity was however ambiguous or contradictory, ranging from encouraging moderate activity to discouraging intensive activity, creating a context of ill-adapted practitioner support with regard to exercise as observed in other contexts such as arthritis (Hunt and Papathomas 2020). "Healthy living" expectations also covered a wide range of normative behaviours including diet, alcohol, "partying" or levels of rest. In this way health messages attempted to influence a wide range of social activity in the everyday lives of PLWH, constituting biopedagogies regarding recommended or expected physical and social behaviours (Rail 2012; Wright and Harwood 2012). Biopedagogies concerning health behaviours appeared as key elements of illness narratives, embodied and signified differently depending on a range of factors including physical experiences of fatigue or physical activity.

Physical activity was most often construed as either a moral responsibility or a means of health management, as observed with other chronic illnesses such as arthritis or multiple sclerosis, where exercise often emerged as a way to "preserve health" (Hunt and Papathomas 2020) and "control a chronic illness and keep physical deterioration at bay" (Richardson, Barstow, and Motl 2019). In other cases physical activity constituted a mode of "battling" HIV, through action or positive energy. Since the pioneering work by Susan Sontag (1989) noting the widespread use of military terminology to describe the "fight" against illnesses like HIV/AIDS, narratives of "combating" HIV have been documented (Pierret 2007). In the case of bodybuilders, strength and muscle have been wielded as proof of "winning" over illness and illness stereotypes such as frailty (Ferez and Perera 2018). Their narratives were of empowerment, of a body and self at war with 
illness. This corresponds to a dominant illness narrative, present in media accounts, where "accounts of anyone suffering from a life threatening illness are almost invariably couched in terms of a courageous 'fight' by the sufferer” (Kelly and Dickinson 1997, 268, cited in Bury 2001, 279).

In most narratives, however, the body emerged as vulnerable, whether weak and ill or tenuously robust thanks to exercise, or as needing protection or preservation from over-exertion. These representations led to discourse promoting physical activity as necessarily moderate to maintain health and energy ("Healthy because sporty"), or the exclusion of physical activity altogether to manage fatigue and protect the body ("No sport due to fatigue"). Physical activity as "risky" corresponds to predominant social representations regarding physical activity for populations viewed as "fragile" such as older adults (Emile et al. 2014) or people living with cancer (Falzon et al. 2012) or HIV (Gray et al. 2018). In contrast, public health messages in France promote physical activity for "fragile" populations to improve or preserve health (Honta and Illivi 2019). In this regard, the chronically ill simultaneously endure normative pressure to engage in physical activity and stereotypes which hinder physical inactivity. These contradicting representations were reflected in the ambivalent social and medical discourses about physical activity: more or less encouraged, but not "too much". Certain profiles ("No sport due to fatigue") seemed particularly susceptible to such conflicting representations, feeling incapable of physical activity but guilty about inactivity.

Beyond its links with physical activity, fatigue emerged as more or less experienced, symptomatic of HIV or incapacitating. The distinctions between "normal" (chosen) and HIVrelated (borne) fatigue were coherent with distinctions that researchers have made between "acute" and "chronic" fatigue, associated respectively with exertion and illness (Kluger, Krupp, 
and Enoka 2013). This distinction also supports previous research on meanings attributed to chronic fatigue as symptomatic of illness/ HIV (Schuft et al. 2018).

Overall, the ideal types revealed four constellations of meanings and experiences attributed to fatigue and physical activity, but also four means of narrating the self, situated between opposing representations of physical health (healthy or ill) and the body-self (vulnerable or robust). For some, physical activity was part of dominant narratives about "winning" over illness or keeping it at bay, and distancing the body-self from incapacity, handicap or illness. For others physical activity was dissociated from normative behaviours for oneself, the body-self viewed as too ill, or else inactive due to alternative "excuses". Discourses on the self living with HIV have likewise been shown to vacillate between recognizing and denying diminished health or capabilities (Ferez et al. 2014), denial being one adaptive response to living with chronic illness (Telford, Kralik, and Koch 2006). In this way, fatigue and physical activity constituted key dimensions of the way PLWH portray the body-self in varying shades of healthy or ill, capable or handicapped. In other words, the interpretations and portrayals of physical experiences illustrate - but also participate in "crafting" - understandings of the body-self living with HIV.

Despite providing an analytical framework to depict a diversity of discourses, ideal types also entail drawbacks, simplifying the view of complex social realities through an angle that is inevitably - influenced by researcher interpretation (Smith and McGannon 2018; Sparkes and Smith 2009). The theoretical continuums in terms of physical activity and fatigue levels sought to partly compensate for the limited frames of analysis in ideal types, and to add complexity to the understanding of the social construction of recounted experience. Further research might also seek to consider more diverse illness symptoms or health behaviors - beyond fatigue and physical activity - longitudinally, and among a larger panel of participants. Lastly, further research may 
seek to better understand how social stratifications along lines of gender, socioeconomic status or handicap status impact illness experiences and narratives of the body-self.

\section{Conclusion}

Considered in relation to individuals' physical experiences in terms of fatigue and physical activity, the ideal type narratives exemplified diverse experiences and interpretations of chronic fatigue and physical activity, as well their interrelations. These physical dimensions of the HIV experience constituted key components of narratives about the body and self, situated between healthy and ill, vulnerable and robust, tired and active, needing and heeding expected "healthy living" behaviours. The results shed light on the importance of the body and physical experiences in identity work and the experience of chronic illness. More largely, they illustrate the role of socio-political discourses about health and illness, and different ways in which dominant biopedagogies are embraced, embodied or resisted. The results invite (re)consideration of how health messages or HIV-specific interventions could be adapted to lessen the predominance of chronic illness in discourses about the body-self, and limit the moral regulation of health behaviours and lifestyle choices among people living with chronic illness.

\section{REFERENCES}

Alexias, George, Manos Savvakis, and Ifigenia Stratopoulou. 2016. 'Embodiment and Biographical Disruption in People Living with HIV/AIDS (PLWHA)'. AIDS Care 28 (5): 585-90. https://doi.org/10.1080/09540121.2015.1119782.

ANRS. 2018. 'Épidémiologie de l'infection VIH En France 2013-2018'. ANRS Report.

Atkinson, Paul. 2009. 'Illness Narratives Revisited: The Failure of Narrative Reductionism'. Sociological Research Online 14 (5): 196-205. https://doi.org/10.5153/sro.2030.

Barroso, Julie, and Joachim G. Voss. 2013. 'Fatigue in HIV and AIDS: An Analysis of Evidence'. The Journal of the Association of Nurses in AIDS Care: JANAC 24 (1 Suppl): S5-14. https://doi.org/10.1016/j.jana.2012.07.003. 
Baumgartner, Lisa M., and Keegan N. David. 2009. 'Accepting Being Poz: The Incorporation of the HIV Identity Into the Self'. Qualitative Health Research 19 (12): 1730-43. https://doi.org/10.1177/1049732309352907.

Bergamaschi, Alessandro, Fabienne d'Arripe-Longueville, Laura Gray, Serge Colson, Cecile Goujard, Sylvain Ferez, Isabelle Rouanet, et al. 2019. 'Perceived HIV-Related Physical Fatigue, Sociodemographic Characteristics and Physical Activity: A Cross-Sectional Study'. Journal of Clinical Nursing 28 (11-12): 2147-56. https://doi.org/10.1111/jocn.14793.

Braun, Virginia, and Victoria Clarke. 2019. 'Reflecting on Reflexive Thematic Analysis'. Qualitative Research in Sport, Exercise and Health 11 (4): 589-97. https://doi.org/10.1080/2159676X.2019.1628806.

- - - 2021. 'To Saturate or Not to Saturate? Questioning Data Saturation as a Useful Concept for Thematic Analysis and Sample-Size Rationales'. Qualitative Research in Sport, Exercise and Health 13 (2): 201-16. https://doi.org/10.1080/2159676X.2019.1704846.

Bury, Mike. 2001. 'Illness Narratives: Fact or Fiction?' Sociology of Health \& Illness 23 (3): 263-85. https://doi.org/10.1111/1467-9566.00252.

Charmaz, Kathy. 2002. 'The Self as Habit: The Reconstruction of Self in Chronic Illness': OTJR: Occupation, Participation and Health 22 (1): 31S-41S. https://doi.org/10.1177/15394492020220S105.

Christiansen, Ask Vest, Anders Schmidt Vinther, and Dimitris Liokaftos. 2017. 'Outline of a Typology of Men's Use of Anabolic Androgenic Steroids in Fitness and Strength Training Environments'. Drugs: Education, Prevention and Policy 24 (3): 295-305. https://doi.org/10.1080/09687637.2016.1231173.

Ciambrone, Desire'e. 2001. 'Illness and Other Assaults on Self: The Relative Impact of HIV/AIDS on Women's Lives'. Sociology of Health \& IIIness 23 (July): 517-40. https://doi.org/10.1111/14679566.00263.

Clarke, Juanne N., and Susan James. 2003. 'The Radicalized Self: The Impact on the Self of the Contested Nature of the Diagnosis of Chronic Fatigue Syndrome'. Social Science \& Medicine 57 (8): 138795. https://doi.org/10.1016/S0277-9536(02)00515-4.

Conrad, Peter, and Kristin K. Barker. 2010. 'The Social Construction of Illness: Key Insights and Policy Implications'. Journal of Health and Social Behavior 51 (1): S67-79. https://doi.org/10.1177/0022146510383495.

Costa, Jessica de Mattos, Thiago Silva Torres, Lara Esteves Coelho, and Paula Mendes Luz. 2018. 'Adherence to Antiretroviral Therapy for HIV/AIDS in Latin America and the Caribbean: Systematic Review and Meta-Analysis'. Journal of the International AIDS Society 21 (1): e25066. https://doi.org/10.1002/jia2.25066.

Courtenay, W. H. 2000. 'Constructions of Masculinity and Their Influence on Men's Well-Being: A Theory of Gender and Health'. Social Science \& Medicine 50 (10): 1385-1401. https://doi.org/10.1016/S0277-9536(99)00390-1.

Dray-Spira, Rosemary, K Wilson d'Almeida, C Aubrière, F Marcellin, B Spire, F Lert, and Vespa group. 2013. 'État de Santé de La Population Vivant Avec Le VIH En France Métropolitaine En 2011 et Caractéristiques Des Personnes Récemment Diagnostiquées. Premiers Résultats de l'enquête ANRS-Vespa2'. Bulletin Épidémiologique Hebdomadaire 26-27: 285-92.

Duval, Estelle, Sylvain Ferez, Julie Thomas, and Laura Schuft. 2016. 'La construction de la valorisation de l'activité physique : le rôle des associations VIH'. Santé Publique S1 (HS): 89-100. https://doi.org/10.3917/spub.160.0089.

Emile, Mélanie, Aïna Chalabaev, Yannick Stephan, Karine Corrion, and Fabienne D’Arripe-Longueville. 2014. 'Aging Stereotypes and Active Lifestyle: Personal Correlates of Stereotype Internalization 
and Relationships with Level of Physical Activity among Older Adults'. Psychology of Sport and Exercise 15: 198-204. https://doi.org/10.1016/j.psychsport.2013.11.002.

Falzon, Charlène, Aïna Chalabaev, Laura Schuft, Christophe Brizzi, Marion Ganga, and Fabienne D’ArripeLongueville. 2012. 'Beliefs about Physical Activity in Sedentary Cancer Patients: An In-Depth Interview Study in France'. Asian Pacific Journal of Cancer Prevention : APJCP 13 (December): 6033-38. https://doi.org/10.7314/APJCP.2012.13.12.6033.

Ferez, Sylvain, and Jean-Pierre Luauté. 2008. 'L'activité Physique et Sportive Comme Outil Médicopsychologique ? Étude de l'offre de Pratiques En Direction Des Personnes Infectées Par Le VIH'. Annales Medico-Psychologiques 166: 847-49. https://doi.org/10.1016/j.amp.2008.10.011.

Ferez, Sylvain, Estelle Marin-Duval, Julie Thomas, Stéphane Héas, and Patrick Fougeyrollas. 2014. 'Continuer à s'engager Dans Des Loisirs Après Avoir Été Infecté Au VIH : Entre Quête de Normalité et Prescription Sociale'. Loisir et Société / Society and Leisure 37 (2): 205-23. https://doi.org/10.1080/07053436.2014.936162.

Ferez, Sylvain, and Éric Perera. 2018. "'Ceux qui disent que je suis malade, je les invite à venir prendre l'entraînement avec moi." Devenir body-builder à l'épreuve du VIH'. Staps, no. 119 (March): 95116. https://doi.org/10.3917/sta.119.0095.

Frank, Arthur W. 1993. 'The Rhetoric of Self-Change: Illness Experience as Narrative'. The Sociological Quarterly 34 (1): 39-52.

Geary, Cindy, Warren Parker, Susan Rogers, Erica Haney, Carolyne Njihia, Amaha Haile, and Eddy Walakira. 2014. 'Gender Differences in HIV Disclosure, Stigma, and Perceptions of Health'. AIDS Care 26 (11): 1419-25. https://doi.org/10.1080/09540121.2014.921278.

Goffman, Erving. 1963. Stigma: Notes on the Management of Spoiled Identity. Englewood Cliffs, N.J.: Prentice-Hall.

Gray, Laura, Aïna Chalabaev, Jacques Durant, Eric Rosenthal, Christian Pradier, Martin Duracinsky, Isabelle Rouanet, Laura Schuft, Serge S. Colson, and Fabienne d'Arripe-Longueville. 2018. 'Exercise Stereotypes and Fatigue in People Living with HIV: Does Self-Efficacy Play a Mediating or a Moderating Role?' Archives of Public Health 76 (April). https://doi.org/10.1186/s13690-0180269-1.

Gray, Laura, Laura Schuft, Alessandro Bergamaschi, Valentine Filleul, Serge S. Colson, and Fabienne d'Arripe-Longueville. 2019. 'Perceived Barriers to and Facilitators of Physical Activity in People Living with HIV: A Qualitative Study in a French Sample'. Chronic Illness, February, 1742395319826638. https://doi.org/10.1177/1742395319826638.

Harmon, JL, Julie Barroso, Brian W. Pence, Jane Leserman, and N Salahuddin. 2008. 'Demographic and Illness-Related Variables Associated with HIV-Related Fatigue.' The Journal of the Association of Nurses in Aids Care : Janac 19 (2): 90-97. https://doi.org/10.1016/j.jana.2007.08.005.

Honta, Marina, and Frédéric Illivi. 2019. 'Le prix de l'innovation : capacités des opérateurs et réception des programmes de lutte contre la sédentarité'. Innovations $N^{\circ} 60$ (3): 201-22.

Hughes, Alicia M., Lucy Campbell, Hannah Graham, Frank Post, and Trudie Chalder. 2020. 'A Biopsychosocial Approach to HIV Fatigue: A Cross-Sectional and Prospective Analysis to Identify Key Modifiable Factors'. Behavioral Medicine 0 (0): 1-9. https://doi.org/10.1080/08964289.2020.1712582.

Hunt, Emily R., and Anthony Papathomas. 2020. 'Being Physically Active through Chronic Illness: Life Experiences of People with Arthritis'. Qualitative Research in Sport, Exercise and Health 12 (2): 242-55. https://doi.org/10.1080/2159676X.2019.1601637.

Jenkin, Peter, Tina Koch, and Debbie Kralik. 2006. 'The Experience of Fatigue for Adults Living with HIV'. Journal of Clinical Nursing 15 (9): 1123-31. https://doi.org/10.1111/j.1365-2702.2006.01343.x. 
Jong, Eefje, Lisanne A. Oudhoff, Cynthia Epskamp, Marlies N. Wagener, Miranda van Duijn, Steven Fischer, and Eric Cm van Gorp. 2010. 'Predictors and Treatment Strategies of HIV-Related Fatigue in the Combined Antiretroviral Therapy Era'. AIDS 24 (10): 1387-1405. https://doi.org/10.1097/QAD.0b013e328339d004.

Kelly, Michael P., and Hilary Dickinson. 1997. 'The Narrative Self in Autobiographical Accounts of Illness'. The Sociological Review 45 (2): 254-78. https://doi.org/10.1111/1467-954X.00064.

Kluger, Benzi M., Lauren B. Krupp, and Roger M. Enoka. 2013. 'Fatigue and Fatigability in Neurologic Illnesses: Proposal for a Unified Taxonomy'. Neurology 80 (4): 409-16. https://doi.org/10.1212/WNL.0b013e31827f07be.

Lert, France, M Annequin, L Tron, C Aubrière, C Hamelin, B Spire, R Dray-Spira, and Vespa group. 2013. 'Socioeconomic Conditions of People Living with HIV Followed at Hospital in Metropolitan France. Results of the ANRS-VESPA2 Study'. Bulletin Épidémiologique Hebdomadaire 26-27: 293-99.

Mackworth-Young, Constance R. S., Virginia Bond, and Alison Wringe. 2020. 'Secrets and Silence: Agency of Young Women Managing HIV Disclosure'. Medical Anthropology 39 (8): 720-34. https://doi.org/10.1080/01459740.2020.1764551.

Marsicano, Elise, Rosemary Dray-Spira, France Lert, Cindy Aubrière, Bruno Spire, Christine Hamelin, and ANRS-Vespa2 study group. 2014. 'Multiple Discriminations Experienced by People Living with HIV in France: Results from the ANRS-Vespa2 Study'. AIDS Care 26: S97-106. https://doi.org/10.1080/09540121.2014.907385.

McGrath, Janet W., Margaret S. Winchester, David Kaawa-Mafigiri, Eddy Walakira, Florence Namutiibwa, Judith Birungi, George Ssendegye, et al. 2014. 'Challenging the Paradigm: Anthropological Perspectives on HIV as a Chronic Disease'. Medical Anthropology 33 (4): 303-17. https://doi.org/10.1080/01459740.2014.892483.

Mennesson, Christine. 2011. 'Socialisation familiale et investissement des filles et des garçons dans les pratiques culturelles et sportives associatives'. Réseaux 4 (168-169): 87-110. https://doi.org/10.3917/res.168.0087.

Newman, Christy E., Asha Persson, Angela Miller, and Rebecca J. Brown. 2016. “Just Take Your Medicine and Everything Will Be Fine": Responsibilisation Narratives in Accounts of Transitioning Young People with HIV into Adult Care Services in Australia'. AIDS Care 28 (1): 131-36. https://doi.org/10.1080/09540121.2015.1069790.

Nowell, Lorelli S., Jill M. Norris, Deborah E. White, and Nancy J. Moules. 2017. 'Thematic Analysis: Striving to Meet the Trustworthiness Criteria'. International Journal of Qualitative Methods 16 (1). https://doi.org/10.1177/1609406917733847.

Olson, Karin, Oksana Zimka, and Eleanor Stein. 2015. 'The Nature of Fatigue in Chronic Fatigue Syndrome': Qualitative Health Research 25 (10): 1410-22. https://doi.org/10.1177/1049732315573954.

Olsson, Malin, Lena Stafström, and Siv Söderberg. 2013. 'Meanings of Fatigue for Women With Parkinson's Disease:' Qualitative Health Research 23 (6): 741-48. https://doi.org/10.1177/1049732313482398.

Perazzo, Joseph D., Allison R. Webel, Joachim G. Voss, and Maryjo Prince-Paul. 2017. 'Fatigue Symptom Management in People Living With Human Immunodeficiency Virus'. Journal of Hospice \& Palliative Nursing 19 (2): 122. https://doi.org/10.1097/NJH.0000000000000329.

Persson, Asha. 2005. 'Facing HIV: Body Shape Change and the (in)Visibility of Illness'. Medical Anthropology 24 (3): 237-64. https://doi.org/10.1080/01459740500182683.

Pierret, Janine. 2007. 'An Analysis over Time (1990-2000) of the Experiences of Living with HIV'. Social Science \& Medicine (1982) 65 (November): 1595-1605. https://doi.org/10.1016/j.socscimed.2007.06.017. 
Quiles, Norberto N., Joseph T. Ciccolo, and Carol Ewing Garber. 2017. 'Association Between Physical Activity, Depression, and Diabetes in Urban-Dwelling People Living with HIV'. The Journal of the Association of Nurses in AIDS Care: JANAC 28 (6): 838-48. https://doi.org/10.1016/j.jana.2017.06.015.

Rail, Geneviève. 2012. 'The Birth of the Obesity Clinic: Confessions of the Flesh, Biopedagogies and Physical Culture'. Sociology of Sport Journal 29: 227-53. https://doi.org/10.1123/ssj.29.2.227.

Richardson, Emma V., Elizabeth A. Barstow, and Robert W. Motl. 2019. 'A Narrative Exploration of the Evolving Perception of Exercise among People with Multiple Sclerosis'. Qualitative Research in Sport, Exercise and Health 11 (1): 119-37. https://doi.org/10.1080/2159676X.2018.1509369.

Saunders, Benjamin, Julius Sim, Tom Kingstone, Shula Baker, Jackie Waterfield, Bernadette Bartlam, Heather Burroughs, and Clare Jinks. 2018. 'Saturation in Qualitative Research: Exploring Its Conceptualization and Operationalization'. Quality \& Quantity 52 (4): 1893-1907. https://doi.org/10.1007/s11135-017-0574-8.

Schuft, Laura, Estelle Duval, Julie Thomas, and Sylvain Ferez. 2018. 'To Be or Not to Be Sick and Tired: Managing the Visibility of HIV and HIV-Related Fatigue'. Health. An Interdisciplinary Journal 22 (4): 317-36. https://doi.org/10.1177/1363459317693406.

Smith, Brett, and Kerry McGannon. 2018. 'Developing Rigor in Qualitative Research: Problems and Opportunities within Sport and Exercise Psychology'. International Review of Sport and Exercise Psychology 11 (1): 101-21. https://doi.org/10.1080/1750984X.2017.1317357.

Smith, Rachel, Kelly Rossetto, and Brittany L. Peterson. 2008. 'A Meta-Analysis of Disclosure of One's HIV-Positive Status, Stigma and Social Support'. AIDS Care 20 (10): 1266-75. https://doi.org/10.1080/09540120801926977.

Sontag, Susan. 1989. AIDS and Its Metaphors. New York: Farrar, Straus and Giroux.

Sparkes, Andrew, and Brett Smith. 2009. 'Judging the Quality of Qualitative Inquiry: Criteriology and Relativism in Action'. Psychology of Sport and Exercise 10 (5): 491-97. https://doi.org/10.1016/j.psychsport.2009.02.006.

Swedberg, Richard. 2017. 'How to Use Max Weber's Ideal Type in Sociological Analysis'. Journal of Classical Sociology 18 (3): 181-96. https://doi.org/10.1177/1468795X17743643.

Telford, Kerry, Debbie Kralik, and Tina Koch. 2006. 'Acceptance and Denial: Implications for People Adapting to Chronic Illness: Literature Review'. Journal of Advanced Nursing 55 (4): 457-64. https://doi.org/10.1111/j.1365-2648.2006.03942.x.

Thomas, Carol. 2010. 'Negotiating the Contested Terrain of Narrative Methods in Illness Contexts'. Sociology of Health \& Illness 32 (4): 647-60. https://doi.org/10.1111/j.1467-9566.2010.01239.x.

Thomas, Julie, Estelle Duval, Éric Perera, and Sylvain Ferez. 2014. 'La perception de l'activité physique comme mode de prise de charge du VIH : effets de la visibilité du corps sur les stratégies de gestion d'une "maladie chronique"'. Science \& Motricité, no. 84: 99-110. https://doi.org/10.1051/sm/2013081.

Thorpe, Rachel D. 2009. "Doing" Chronic Illness? Complementary Medicine Use among People Living with HIV/AIDS in Australia'. Sociology of Health \& IIIness 31 (3): 375-89. https://doi.org/10.1111/j.1467-9566.2008.01137.x.

Tracy, Sarah J. 2010. 'Qualitative Quality: Eight “Big-Tent” Criteria for Excellent Qualitative Research'. Qualitative Inquiry 16 (10): 837-51. https://doi.org/10.1177/1077800410383121.

Voigt, Natalie, Hwayoung Cho, and Rebecca Schnall. 2018. 'Supervised Physical Activity and Improved Functional Capacity among Adults Living with HIV: A Systematic Review'. Journal of the Association of Nurses in AIDS Care 29 (5): 667-80. https://doi.org/10.1016/j.jana.2018.05.001.

Webel, Allison R., Joe Perazzo, Michael Decker, Christine Horvat-Davey, Abdus Sattar, and Joachim Voss. 2016. 'Physical Activity Is Associated with Reduced Fatigue in Adults Living with HIV/AIDS'. Journal of Advanced Nursing 72 (12): 3104-12. https://doi.org/10.1111/jan.13084. 
Wouters, Edwin, and Katinka De Wet. 2016. 'Women's Experience of HIV as a Chronic Illness in South Africa: Hard-Earned Lives, Biographical Disruption and Moral Career'. Sociology of Health \& IIIness 38 (4): 521-42. https://doi.org/10.1111/1467-9566.12377.

Wright, Jan, and Valerie Harwood. 2012. Biopolitics and the 'Obesity Epidemic'. New York: Routledge. Zhu, Zheng, Rui Zhao, and Yan Hu. 2019. 'Symptom Clusters in People Living With HIV: A Systematic Review'. Journal of Pain and Symptom Management 58 (1): 115-33. https://doi.org/10.1016/j.jpainsymman.2019.03.018. 